\title{
Study on an environmental simulation system of low/high temperature for great space
}

\author{
Weike Pang ${ }^{1, a^{*}}$, Tianping Liü, b Jun Wang ${ }^{1, c}$ \\ ${ }^{1}$ School of Aeronautic Science and Engineering, Beihang University, Beijing, China \\ avke_java@163.com, bliutp@buaa.edu.cn, cwangjun@buaa.edu.cn
}

\begin{abstract}
Keywords: air turbine, dew-point temperature, self-adaption adjustment
Abstract: An environmental simulation system of low/high temperature for great space that is for a function test on its unfolding structure of some aerials is designed based on air refrigeration principle. According to its practical run at chamber temperature of $-70^{\circ} \mathrm{C}$, its main parts such as driers, turbines, environmental chamber are investigated. The experiment results show that it is viable to adopting refrigeration way of air turbine for an environmental system of great space simulating low/high temperature. It is not only fulfilled with their temperature demand during those experiments, but also their humidity demand. The subsystem of driers works well and matches with its regeneration, which the wave of dew-point temperature reduces during its switch stage. Meanwhile, the energy is saved. The air turbine could adjust its cooling capacity by itself according to load changes. The pressure of environmental chamber keeps to be about 30 100Pa, so the whole system could run safely, stably and reliably.
\end{abstract}

\section{Background}

The technology of environmental simulation is one of important conditions for present researches. After an appropriate laboratory that could simulate their practical run environment is constructed, their function parameters of new developed products could be tested and analyzed here. It will cut down their improved and optimized periods greatly. As a result, their developed efficiency of new products goes up ${ }^{[1]}$.

The environmental simulation system of low and high temperature mainly focuses on the laboratory temperature. Additionally, those parameters of humidity, pressure and cleanness are asked to give some control strategies ${ }^{[2]}{ }^{[3]}$. As far as aeronautics and astronautics projects, there are some unique traits about space environmental simulation ${ }^{[4]}$. An environmental simulation system for function test of some aerials affiliated to astronautics institutes is demanded to adjust its chamber temperature from $-100^{\circ} \mathrm{C}$ to $+130^{\circ} \mathrm{C}$. Overall, it takes a refrigeration way of air turbine ${ }^{[5]}$. Based on its run state of non-fog, non-dew and non-frost in the chamber, the subsystems of air driers, refrigeration and chamber are studied with aerial load at lowest temperature of $-70^{\circ} \mathrm{C}$. 


\section{Process principle and project practicality}

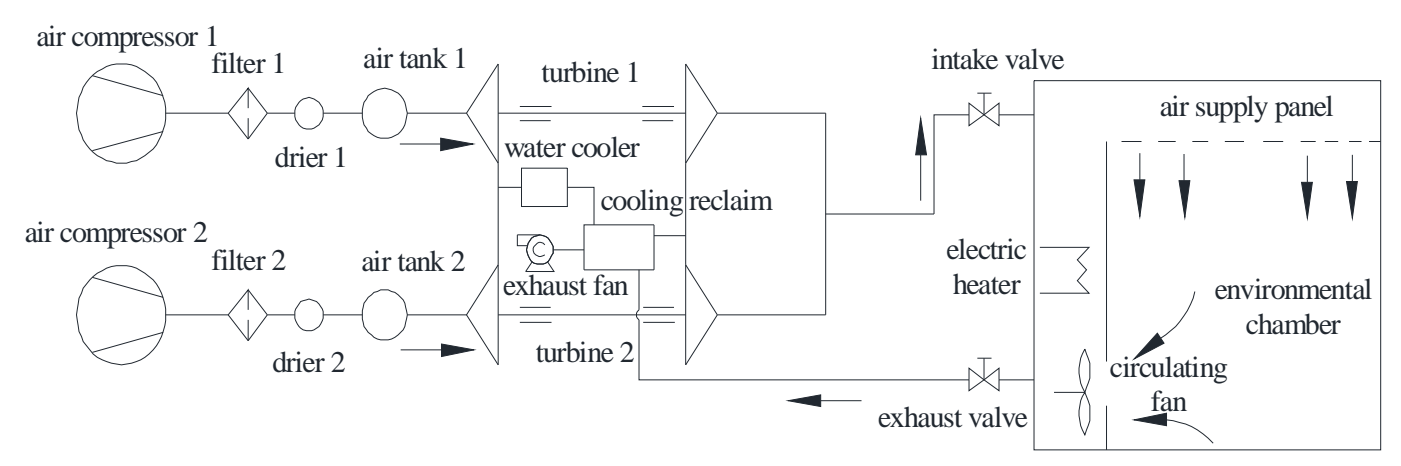

Fig.1 Process principle of the environmental simulation system

As shown in figure 1, outdoor air is compressed firstly by air compressors. After then its pressure becomes high and is referred to as high-pressure air. Next, the high-pressure air goes into driers to remove most of vapor inside air and further becomes dry air of high pressure. The processed preliminarily air is collected in an air tank together and the wave of air current disappears here. The air with steady pressure steps into a boosting-turbine unit to be compressed again, and then cooled in a water cooler. Later, the air cooled by water comes into an energy exchanger with cooling reclaim. The cold air is cooled again by exhaust air whose temperature is lower from the chamber. Consequently, the air becomes colder and reuses lots of cooling by heat transferring. The colder air finally gets into a turbine to swell and drops down its own temperature. At last, the air whose pressure and temperature drop down is gave into the chamber by an intake valve. Now, an environment with low temperature is simulated. Moreover, the turbulence of given air should be down to keep the test zone of products in a stable state. Accordingly, some radiant exchangers are fixed up along indoor walls. They also could be switched to a cooling way of air supply by panels ${ }^{[6]}$.

When an environment of high temperature is simulated, the intake valve and exhaust valve should be shut down. The indoor air is transported through an electric heater by a circulating fan at first. Then the air of high temperature that is heated returns to the chamber by air supply panels. Again and again, the set temperature could get finally.

The practical projects are shown partly in figure 2 and figure 3.

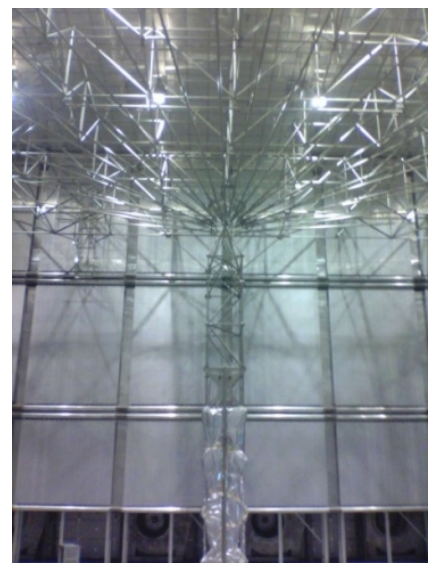

Fig.2 Some zone of the chamber

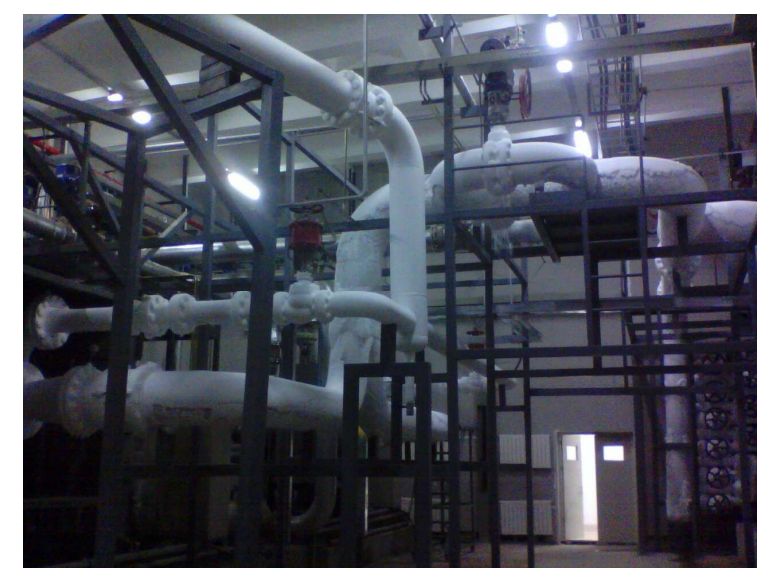

Fig.3 Some zone of the refrigeration subsystem

\section{Data disposal and analysis}

The humidity field of environmental chamber is affected mainly by its dew-point temperature of given air. The moisture content of compressed air processed by driers is an important factor that 
adjusts the humidity field actively. The surplus moisture transferred from primary air should be taken away by the given air. So the drier is a key part to control the humidity. The process of driers is adsorption and regeneration, and its regeneration consists of heating, cooling, and pressure balance respectively.

A drier subsystem is made up of two driers and they work alternately. If one drier is dehumidifying, the other stops to regenerate. The main part of each drier is a pressure container that is defined as tank A and tank B. The pressure trend of two tanks in a whole period is shown in figure 4. The waiting time to work again that one drier finishes its pressure balance starts earlier than the stop time that the other finishes dehumidifying and then switches to heat. According to its practical run, its waiting time is about 30 minutes. Therefore, the drier subsystem could work stably and reliably. So, the wave of dew-point temperature is low during the two driers switch each other. The operating pressure of the drier at a state of dehumidifying is 7bar. The operating pressure of the drier at a state of heating or cooling is 0 (1bar in absolute pressure); its pressure at a state of awaiting return to 7 bar.

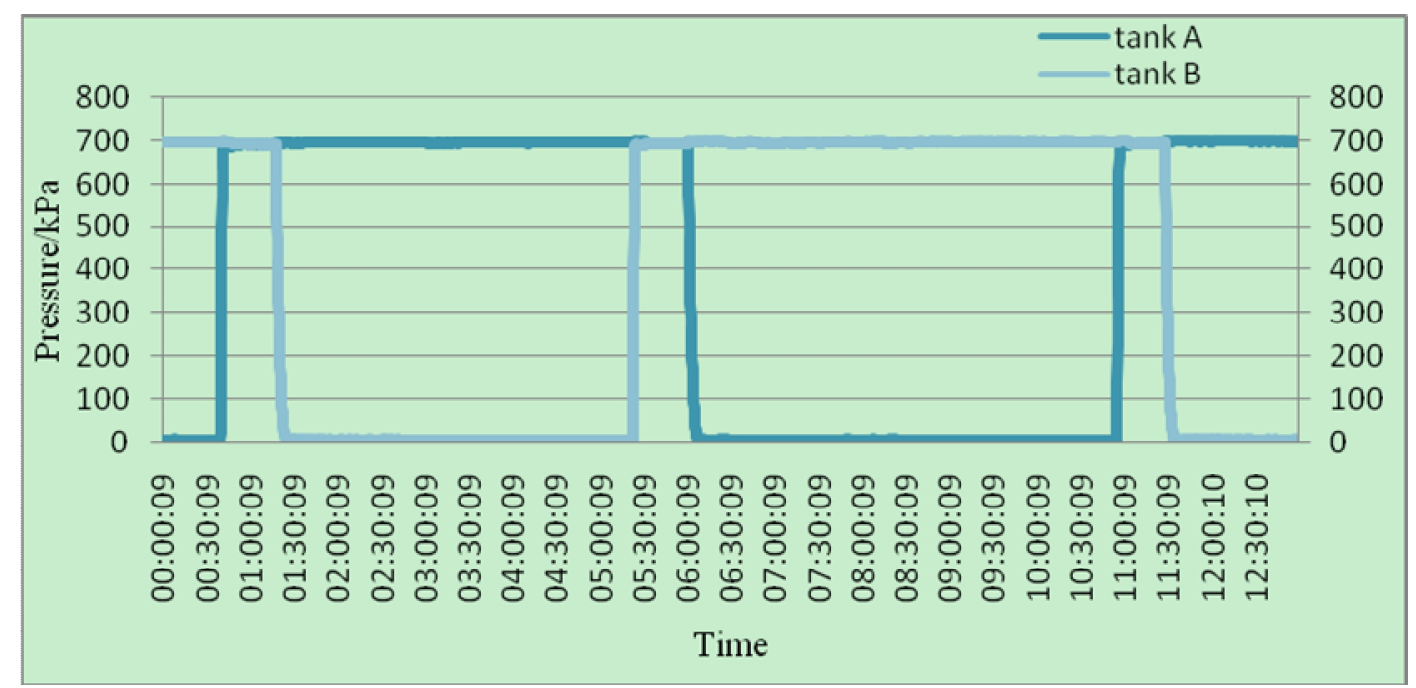

Fig.4 Pressure trend of a drier subsystem

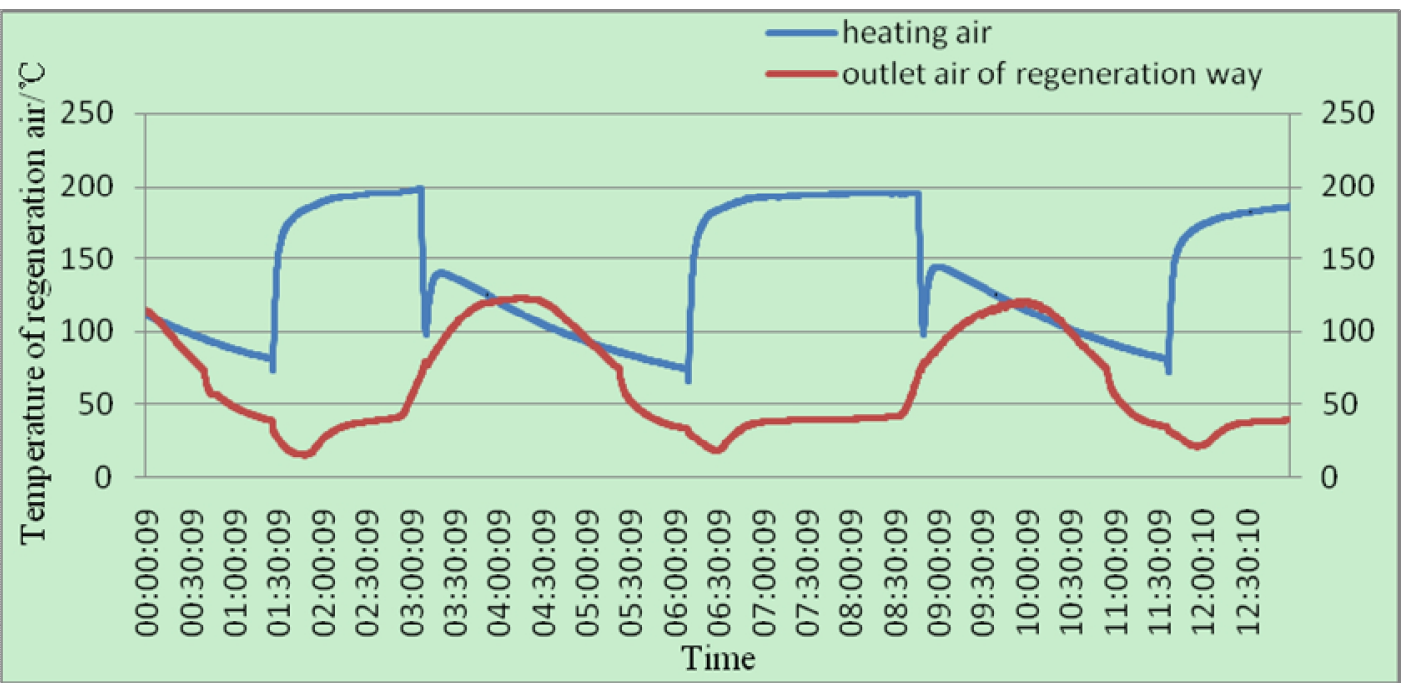

Fig.5 Temperature trend of regeneration air in a drier subsystem

The regeneration of driers is a stage of its desiccant heated and then cooled by air. The air is heated by an electric heater, and it could be heated to a high temperature of $195^{\circ} \mathrm{C}$. The cold source is some throttled air that is taken from the processed dry air. It is about $2 \% \sim 4 \%$ of processed dry air in volume flow. The hot air transfers heat to these desiccants and its temperature goes down 
obviously. With the moisture in desiccants decreases, the heat transferred from hot air goes down gradually. As a result, its temperature of desiccant goes down less than before. When it returns a set temperature, there is little moisture in desiccants. Now, heating is completed to start cooling and then the electric heater turns off. On the other hand, heating time could be set according to its regeneration load. If there is a heavy load, the heating time may increase, but it is not more than three hours. When it is heated overtime, it would be stopped heating compulsively and starts cooling too. So their switch time of two driers is not affected. If there is a light load, the heating time would be shortened so that its input energy reduces and could save some energy. In figure 5, those desiccants switch to cool during its first period according to its air temperature at outlet of regeneration way; and during its second period they switch to cool according to its heating time.

The stage of cooling desiccants goes though common air cooling firstly and then dry air cooling. The first cooling goes short and its time is about several minutes. The second cooling is major and its time is about 2.5 hours. As far as first cooling, after electric heater turns off, the air temperature of heating way goes down greatly. However, there is some remaining heat and it could also heat those desiccants as heating stage before. So its air temperature at outlet of regeneration way goes on to increase as its heating stage. When next cooling starts, the air of heating way is shut and some dry air is throttled to cold air to cool those desiccants again. The air of regeneration way makes those desiccants cool and its own temperature goes up. With the temperature reduction of desiccants, its temperature of outlet air would go up to a maximum. After then, with the temperature reduction of desiccants continually, the air of regeneration way transfers less heat and its temperature goes up less than before. As a result, its temperature of outlet air goes down gradually than before too.

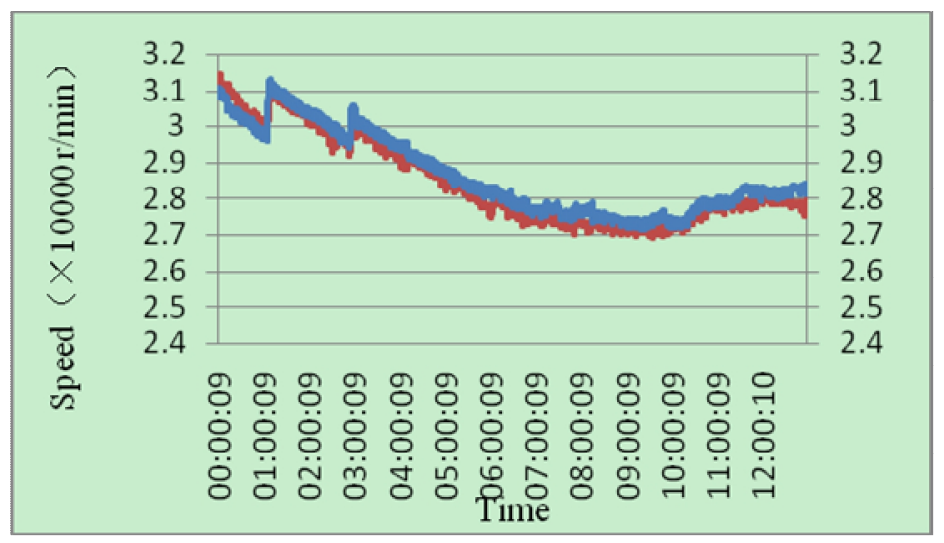

Fig.6 Speed trend of turbines during refrigeration

The practical operating state of air turbines is affected by its cooling load in chamber and some external factors. On one hand, while its temperature of chamber goes down, the whole cooling load reduces gradually. On the other hand, while its suction temperature of turbines goes down, the discharge temperature of turbine decreases. Because the whole cooling load drops, the refrigeration capacity of turbine drops accordingly. Additionally, there is a constant load if its cooling rate of air in chamber is similar. So the suction change of turbines would affect its run. As shown in figure 6, with its low suction and discharge temperature except other constant parameters, its refrigeration capacity would go up; but it would not. That is because its rotational speed goes down and flow rate reduces. Consequently, its refrigeration capacity keeps stable. During temperature-controlled stage, its cooling load in chamber and suction temperature do not change so its rotational speed does not change either. During temperature-return stage, its discharge temperature goes up for its high temperature of suction. Therefore, its rotational speed of turbine goes up to prevent its refrigeration capacity from dropping down. The feature of self-adaption adjustment keeps the system operating 
steadily, and saves lots of energy.

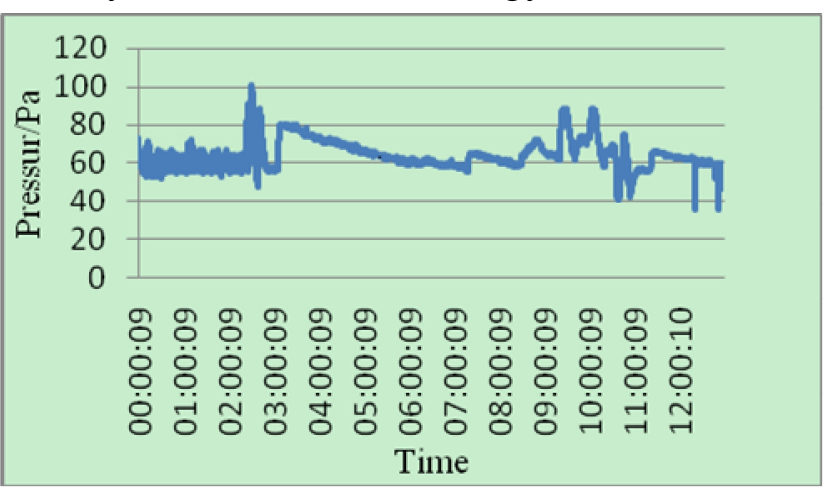

Fig.7 Pressure trend in chamber during test

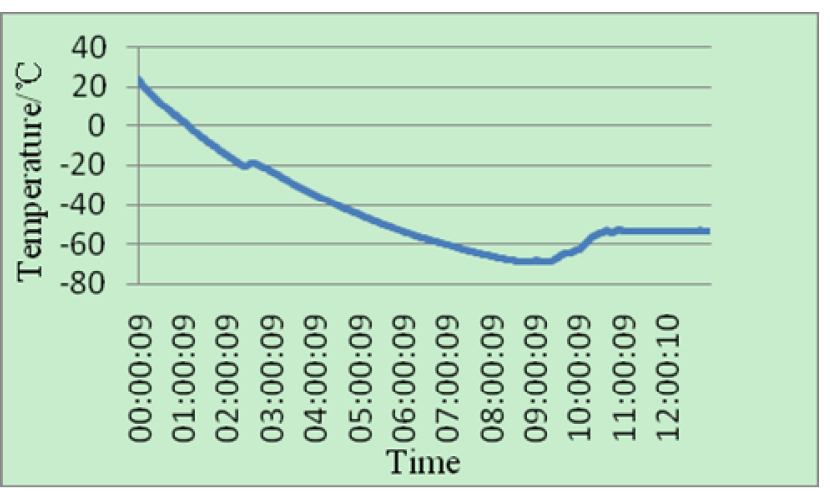

Fig.8 Temperature trend in chamber during test

As shown in figure 7, the pressure of chamber keeps a little higher than outdoors. It is about 30 100 Pa higher. As far as an environment of low temperature, if its pressure of cold air is higher than outdoor, it could prevent external air from getting into its chamber. Comparatively speaking, external air is wetter and its temperature is higher than indoor. Moreover, those insulations of chamber are shrunk at a cold state. Therefore, there may be some gaps and outdoor air may enter into its chamber via these gaps. If so, its thermal and humidity balance would be broken. Consequently, its temperature and humidity in chamber would go up. Seriously, there may be some fog in its chamber and some function tests of developed products are forced to break off.

During its stage of air substitution in chamber, its temperature keeps at about $40^{\circ} \mathrm{C}$. After its dew-point temperature of chamber air goes down at $-70^{\circ} \mathrm{C}$, the cooling stage begins. At the first stage of cooling, cold given air mixes with the dry air in chamber to make its temperature low. When the first stage is over, its temperature could decrease at about $-20^{\circ} \mathrm{C}$ as shown in figure 8 . Next, at the second stage, the cold given air is switched to radiant exchangers in chamber. Its temperature of chamber goes on to reduce by a way of indirect cooling. On the other hand, during its switch stage at $-20^{\circ} \mathrm{C}$, there is about 30 minutes for temperature stabilization. So there is thermal adaption time for chamber materials. Then, according to function tests of this product, the temperature of chamber goes down at $-68^{\circ} \mathrm{C}$. Meanwhile, the key drive parts of this product also goes down at $-68^{\circ} \mathrm{C}$ though they are heating locally by some micro heaters at the same time. After then, its temperature of chamber begins to return. During its return, the practical unfolding stage of this tested aerial at low temperature is simulated. About an hour later, its temperature of chamber return at $-53^{\circ} \mathrm{C}$ and the aerial unfolding is over. Finally, according to its test need, the stable temperature field could keep some time and then return as outdoor environment.

\section{Conclusions}

Based on its practical run, it is viable to adopting refrigeration way of air turbine for an environmental system of great space simulating low/high temperature. It is not only fulfilled with their temperature demand during those experiments, but also their humidity demand. Some results shows following:

1) The subsystem of driers works well and matches with its regeneration, which the wave of dew-point temperature reduces during its switch stage. Meanwhile, the energy is saved.

2) The air turbine could adjust its cooling capacity by itself according to load changes.

3) The pressure of environmental chamber keeps to be about 30 100Pa, so the whole system could run safely, stably and reliably. 


\section{References}

[1] Wang Jun. Present status and development of environment simulation technology in China [J]. Aerospace manufacturing technology, 2004.08

[2] Chang Haijuan. Study on Pressure Control Strategy of High-altitude Multi Environmental Parameter Simulation Cabin System [J]. Acta Armamentarii, 2008, 29(11)

[3] Li Ke, Pang Liping, Liu Wangkai. System model simulation and control method used in environmental simulation chambers [J]. Journal of Beijing University of Aeronautics and Astronautics, 33 (5)

[4] Zhu Yu. Feature and present situation of space environmental simulation with the develop trend in China [J]. Science information of Jiangsu, 2013.12

[5] Du Jiantong. Characteristics and Key Technologies for Air Cycle Refrigerating [J]. Cryogenics and Superconductivity, 1999, 27 (3)

[6] Cui Yi. Optimization study of simulation on high altitude environmental simulation for large aircraft [J]. Cryogenics, 2008.03 